\title{
Responsive demand in isolated energy systems
}

\author{
D. Livengood ${ }^{1}$, F. C. Sim-Sim ${ }^{2}$, C. S. Ioakimidis ${ }^{2}$ \& R. Larson ${ }^{1}$ \\ ${ }^{1}$ Engineering Systems Division, \\ Massachusetts Institute of Technology, USA \\ ${ }^{2}$ Instituto Superior Técnico, Universidade Técnica de Lisboa, Portugal
}

\begin{abstract}
To make islands more economically and environmentally sustainable, there is interest in expanding local renewable sources of electricity generation to displace portions of electric energy generated by fossil fuels. Integrating these inherently weather-dependent and variable sources is a challenge for grid stability. Responsive demand has long been used as a resource for peak management in both island and mainland systems. We discuss potential benefits of expanding responsive demand to help displace electric energy generated by fossil fuel power plants by adjusting the shape of the demand curve to increase use of electricity generated by renewable sources. Our methods also apply to renewable generation capacity expansion decisions.
\end{abstract}

Keywords: responsive demand, integrating renewables, island electricity systems.

\section{Introduction}

Due to the obvious hardships of being an isolated electrical system, it is a challenge to provide stable and quality electricity service to a small island, or group of islands. Because of their small size, these systems often rely on fossil fuel power plants, most commonly diesel units, as these units are easily dispatched and reliable. However, the reliance on externally processed fuels for geographically isolated systems results in a higher cost for each energy unit produced when compared with mainland systems. The absence of self-reliance in such systems is an impoverishing factor that adds to the costs of insularity and diminishes the attractiveness of the island economically Zhang et al [1]. While there are a number of strategies that could all play a role in reducing reliance on imported fossil fuel, the focus of this paper is on the approach of expanding or 
developing the island's local and renewable energy resources, such as wind, hydro, solar and geothermal power, and to increase this sector's percentage of the island's energy generation.

Renewable energy sources, with the notable exception of geothermal, can suffer from variable and intermittent output, limiting the extent of their use as discussed by Weisser and Garcia [2] and Peças Lopes et al [3]. One of the typical solutions to these challenges has been the use of storage devices $[4,5]$, for example using naturally occurring reservoirs as pumping stations [6]. However, some island geographies may not possess naturally occurring geological structures, such as some of the dry islands in Cape Verde [2]. For islands where large storage systems are either infeasible or impractical, other strategies for balancing the variability of renewable generation sources would be necessary.

The alternative strategy we will be discussing here is responsive demand, where some subset of electricity demand is shifted during the course of a day to help balance uncontrollable changes in the supply of electricity from renewable sources. Such a strategy would allow an island to support a greater integration of renewable energy resources, reducing generation costs and providing a more sustainable system (Hamidi et al [7]).

As a proof of concept, we performed a study of the 2008 electricity supply and demand on the island of Flores in the Azores Archipelago in order to compare the benefits that could have been achieved if some fraction of demand was responsive to real-time signals reporting the availability of electricity generation from renewable sources.

\section{Case study: the island of Flores in the Azores Archipelago}

The Azores Archipelago is located in the North Atlantic Ocean, approximately $1500 \mathrm{~km}$ from the European mainland and $3900 \mathrm{~km}$ from North America. The archipelago is a Portuguese Autonomous Region and is constituted by nine populated islands divided into three geographical groups, West, Central, and East, with a total population of approximately 244,000 persons as of the year 2007 [8].

The fragmentation of the population among the nine islands coupled with the physical distance separating the islands means that nine independent electrical systems of different dimensions must be maintained, without the potential for use of more efficient fossil fuels such as natural gas and without adequate energy production players to create an efficient competitive market. The Program from the current Regional Government [9] recognizes the elevated cost from energy on each unit of added value produced in the region and recognizes that this compromises the Azores' competitiveness in a global market. The Program also correctly states that the richness and variety of local renewable energy resources are a key factor in reducing the region's energy handicap. In fact, the investment in equipment for renewable energy production made in the last few years allowed a savings of $11 \%$ in fuel-oil and 5\% in diesel in 2007 . In addition, the current Governmental Goals state that the region is to obtain, in less than six 
years, $50 \%$ of the electricity supply from renewable and local resources for the aggregated consumption of the Archipelago. Hence, each island is interested in expanding the use of renewable generation on their island.

The island of Flores is part of the West Azores Group (comprised of Flores and Corvo) and has a population of 4099 persons in an area of $\sim 141 \mathrm{~km}^{2}$. The Flores Electrical grid has 3 power plants: a Diesel Thermal plant with a capacity of 2.3 MW, a Hydro Power Plant unit with a capacity of $1.5 \mathrm{MW}$, and a Wind Farm with a capacity of $0.6 \mathrm{MW}$. With the power output data from each generator available in half-hour increments throughout the year of 2008, we will compare various scenarios of scaled levels of electricity generation from the wind farm and hydro power plant to the actual demand required over the course of 2008 to see how much diesel-generated electricity would be displaced by the increased electricity generation of these hypothetical scenarios.

From an annual perspective, increasing the generation of electricity from a scaled-up wind farm and hydro power plant soon surpasses the 11,745 MWh energy demand on the island [10]. For instance, scaling up the wind farm to five times the original size and keeping the hydro power plant at its original size would in theory produce $12,810 \mathrm{MWh}$, which would be adequate to meet the island's energy needs for 2008 and thus would displace 100\% of the dieselgenerated electricity. Unfortunately, without a long-term and large-scale storage system, the additional generation of electricity from the wind farm does not always occur at times when the electricity is needed. In fact, the actual displacement of diesel-generated electricity for this scenario is only $51 \%$, assuming that no energy storage systems are available and thus all excess generation from the renewable sources in any given hour is simply unused.

Table 1 emphasizes the stark discrepancy between "in theory" and "in actuality" when comparing the annual theoretical maximum displacement of diesel-generated electricity and the annual actual displacement of dieselgenerated electricity generated for a range of scenarios that scale up the electricity generated by the wind farm and hydro power plant. Even when scaling up the wind and hydro power plants to absurdly large levels, the actual displacement of diesel-generated electricity never reaches $100 \%$. Considering the grid stability requirements as mentioned in the introduction, the goal of $100 \%$ displacement is at best a thought experiment. However, if $100 \%$ displacement

Table 1: Comparison of theoretical maximum annual displacement and actual annual displacement of diesel-generated electricity by increasing renewable electricity generation.

\begin{tabular}{|c|c|c|c|c|c|c|c|}
\hline $\begin{array}{c}\text { Wind farm } \\
\text { scaling factor }\end{array}$ & 2 & 3 & 5 & 40 & 1 & 2 & 10 \\
\hline $\begin{array}{c}\text { Hydro power plant } \\
\text { scaling factor }\end{array}$ & 1 & 1 & 1 & 1 & 2 & 2 & 10 \\
\hline $\begin{array}{c}\text { Theoretical maximum } \\
\text { annual displacement }\end{array}$ & $29 \%$ & $59 \%$ & $100 \%$ & $100 \%$ & $60 \%$ & $90 \%$ & $100 \%$ \\
\hline $\begin{array}{c}\text { Actual } \\
\text { annual displacement }\end{array}$ & $26 \%$ & $39 \%$ & $51 \%$ & $77 \%$ & $43 \%$ & $57 \%$ & $95 \%$ \\
\hline
\end{tabular}


were the ultimate goal, Table 1 illustrates that this goal would be very difficult to reach under the weather conditions of 2008 utilizing only a scaled-up wind farm and hydro power plant.

Although the theoretical maximum annual displacement of diesel-generated electricity is difficult to obtain, the actual annual displacement of dieselgenerated electricity could be improved if the timing of electricity demand aligned more favorably with hours when there was an excess of electricity generation from the combined outputs of the wind farm and hydro power plant. Determining how much improvement may be attainable via responsive demand programs is the focus of the next section.

\section{Integrating increased renewable generation with responsive demand}

As the level of renewable generation sources increases on an island, the possibility develops that these sources might generate more electricity than is demanded over short time intervals. Focusing on intervals of one hour, our interest is to determine the balancing potential of responsive demand by shifting demand from one hour to another within a given day.

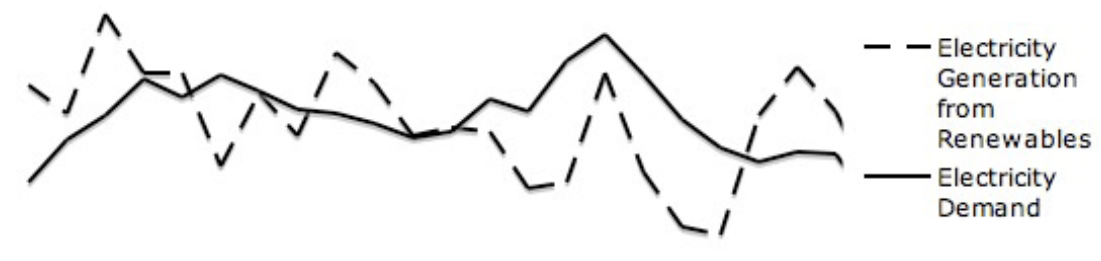

Hour of the Day

Figure 1: Electricity demand and renewable generation on an example day in May 2008.

To illustrate this situation, consider the demand pattern in fig. 1 over 24 hours in early May and the scenario where we have tripled the wind farm's capacity and kept the hydro power plant at its original capacity. On that day, as shown in fig. 1 with the hypothetical renewable generation as the dashed line and the electricity demand level as the solid line, there are some hours where the renewable electricity generation exceeds the electricity demand and there are also some hours where the electricity demand exceeds the renewable electricity generation. It is on days like these where responsive demand could clearly play a role in increasing the utilization of renewable electricity generation and further displacing electricity generated by the diesel power plant. 


\subsection{Frequency of days that could benefit from responsive demand}

Before considering the potential benefit of implementing a responsive demand program for improving the utilization of expanded renewable generation, it is important to first determine for our case study of Flores the number of days in 2008 for which a responsive demand program would prove useful. Looking at the same scenarios illustrated in Table 1, we calculated the number of days in our sample year of 2008 where some hours had excess hypothetical renewable electricity generation and some hours had insufficient hypothetical renewable electricity generation. The results are shown in Table 2 and show that a significant number of days in 2008 are similar to the day analyzed in fig. 1.

This justified the next step of the research, which was to calculate how much additional displacement of diesel-generated electricity could be attained with responsive demand.

Table 2: $\quad$ Number of days in 2008 where responsive demand could provide additional displacement of diesel-generated electricity.

\begin{tabular}{|c|c|c|c|c|c|c|c|}
\hline $\begin{array}{c}\text { Wind farm } \\
\text { scaling factor }\end{array}$ & 2 & 3 & 5 & 40 & 1 & 2 & 10 \\
\hline $\begin{array}{c}\text { Hydro power plant } \\
\text { scaling factor }\end{array}$ & 1 & 1 & 1 & 1 & 2 & 2 & 10 \\
\hline $\begin{array}{c}\text { Number of days similar } \\
\text { to fig. 1 (out of 366) }\end{array}$ & 172 & 228 & 246 & 187 & 163 & 193 & 78 \\
\hline
\end{tabular}

\subsection{Modelling assumptions for responsive demand}

Calculating the effect of responsive demand required a few modelling decisions to be made for this analysis. First and foremost, we assumed that only a subset of the total demand would be available to participate in a responsive demand program. In Flores, for instance, $9 \%$ of the annual electricity demand is for public lighting, which is going to be inflexible with regards to its time of usage [10]. However, other services requiring electricity, such as appliance loads in residences or HVAC systems in commercial buildings, may have flexibility with regards to when that service is provided. In addition, small-scale storage systems (potentially including plug-in electric vehicles) could also be included as an option for responsive demand.

For this model, we made a simplifying assumption not to differentiate between controllable demand and small-scale storage systems. Hence, we decided to model the amount of responsive demand available on a given day as a certain percentage of the total demand for that day. Clearly the details of when responsive demand is available and the times to which it could be shifted will affect the realized benefits of a responsive demand program. A more intricate model of how end users, especially residents, would participate in responsive demand programs of this nature is being developed through related research by two of the authors and their colleagues [11]. Once these dynamics are better 
modelled, an agent-based simulation could provide a more accurate model of the achievable benefits of responsive demand. However, that work is beyond the scope of this paper.

\subsection{Estimating the benefits of responsive demand}

With the assumptions discussed in section 3.2 in place, the analysis for estimating the potential benefits of responsive demand was completed in the following way. For each hour, the scaled renewable generation was compared to the demand for that hour. Two outcomes are possible for each hour: either the electricity generated by the renewable sources would meet and exceed the necessary demand, or it would be insufficient to meet the demand that hour. The baseline scenario of displaced diesel-generated electricity, equivalent to the row of 'actual annual displacement' included in Table 1, was calculated assuming that demand was fixed for each hour. Then, under constraints discussed in more detail in sections 3.3.1 and 3.3.2, demand was allowed to shift from hours of insufficient renewable generation to hours of excess renewable generation in order to determine the additional displacement of diesel-generated electricity that exceeded the Table 1 baseline and was due to responsive demand.

One note is that with the assumption that there is no large-scale energy storage available, any excess electricity generated by the renewables above the demand level in a given hour is assumed to be 'lost'. As mentioned in the introduction, this excess generation clearly poses a challenge for grid operators to maintain grid stability. However, for the analysis at hand, we are simply assuming that operational details of excess generation of renewables will be dealt with via other operational systems. Whether or not the operational challenges of excess generation significantly affect the results of this analysis will be left for future work on this model.

\subsubsection{Benefits of intra-day responsive demand}

For the initial implementation of responsive demand in our model, we assumed that demand would only shift between hours of a given day. To calculate the additional displacement of diesel-generated electricity, we first identified all hours in the day with excess generation from the scaled-up renewables and all hours in the day where the generation from the scaled-up renewables was insufficient to meet the demand in that hour. As long as the day had one or more hours that met each situation described here, then the responsive demand could shift from hours with insufficient renewable generation to hours with excess renewable generation.

Ultimately, there were three constraints on the attainable amount of additional displacement of diesel-generated electricity for any given day: the percentage of total demand that was available as responsive demand, the total excess renewable generation from the hours with excess, and the total amount of displaceable diesel-generated electricity from the hours with insufficient renewable generation. The percentage of total demand available as responsive demand was varied from $1 \%$ to $20 \%$, as illustrated in fig. 2 . The total excess renewable generation and the amount of displaceable diesel-generated electricity for any 
given day varied based on the original demand pattern for that day, the original level of electricity generated by the wind farm and the hydro power plant, and on the scaling factors for the wind farm and hydro power plant used in the current scenario.

Given all of these inputs, the output of the model calculates how much additional displacement of diesel-generated electricity is attainable for each day, and then the daily additional displacements were all summed to determine the annual additional displacement. This additional displacement is then added on to the baseline displacement of the scenario used to scale-up the renewables for that run of the model. The additional annual displacement of diesel-generated electricity was calculated for all of the scenarios included in Table 1, and all scenarios showed similar trends in the gains over their respective Table 1 baselines. To illustrate an example of the additional displacement trends, the results of the scenario with a $3 \mathrm{x}$ scaling factor for the wind farm and $1 \mathrm{x}$ scaling factor for the hydro power plant combination are illustrated in fig. 2 .

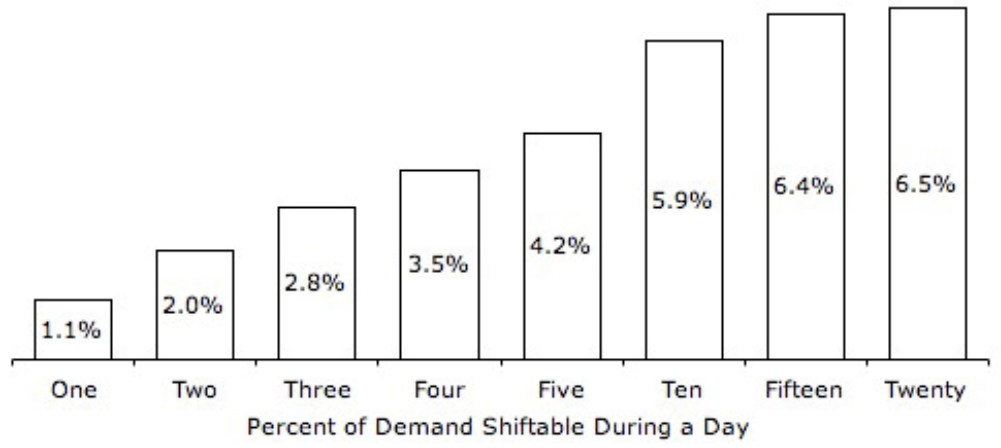

Figure 2: Additional displacement of diesel-generated electricity for scenario of $3 \mathrm{x}$ wind and $1 \mathrm{x}$ hydro due to intra-day responsive demand.

To review, in Table 1 the $3 \mathrm{x}$ wind and $1 \mathrm{x}$ hydro scenario had a theoretical maximum displacement of diesel-generated electricity of $59 \%$ and an actual annual displacement of diesel-generated electricity of 39\%. As fig. 2 shows, the inclusion of responsive demand can narrow the gap between the theoretical and actual annual displacement of diesel-generated electricity by over six percentage points to a potential annual displacement of diesel-generated electricity of $45 \%$.

However, fig. 2 also shows that there are diminishing returns to increasing the percent of demand available for participation in an intra-day responsive demand program. This trend is caused by the fact that as the amount of responsive demand increases, more and more days have either exhausted all excess generation from the renewable sources for that day or have displaced all of the diesel-generated electricity for that day. This motivated our next extension to the model, which analyzes the additional benefits of delaying responsive demand by one day once the intra-day benefits have been exhausted. 


\subsubsection{Benefits of intra-day and one-day delay responsive demand}

In section 3.3.1, responsive demand was limited to shift between hours within a single day. However, if the weather forecast calls for low wind today and high wind tomorrow, some electricity consumers might be willing to delay their demand until tomorrow. To get a sense of the additional benefits of including a one-day delay of demand, we adjusted our model to include inter-day shifting of responsive demand if there was an increase in the additional displacement of diesel-generated electricity.

To focus on the additional benefits from one-day demand delays, fig. 3 like fig. 2 models the scenario of the $3 \mathrm{x}$ scaling factor for the wind farm and $1 \mathrm{x}$ scaling factor for the hydro power plant and shows the resulting increase in diesel-generated electricity displacement as a result of allowing one-day demand delays. Fig. 3 illustrates that incorporating one-day delays in responsive demand provides even closer attainment of the theoretical displacement maximum (59\%) in Table 1. The data for all of the scenarios was modeled and all showed similar trends here as well.

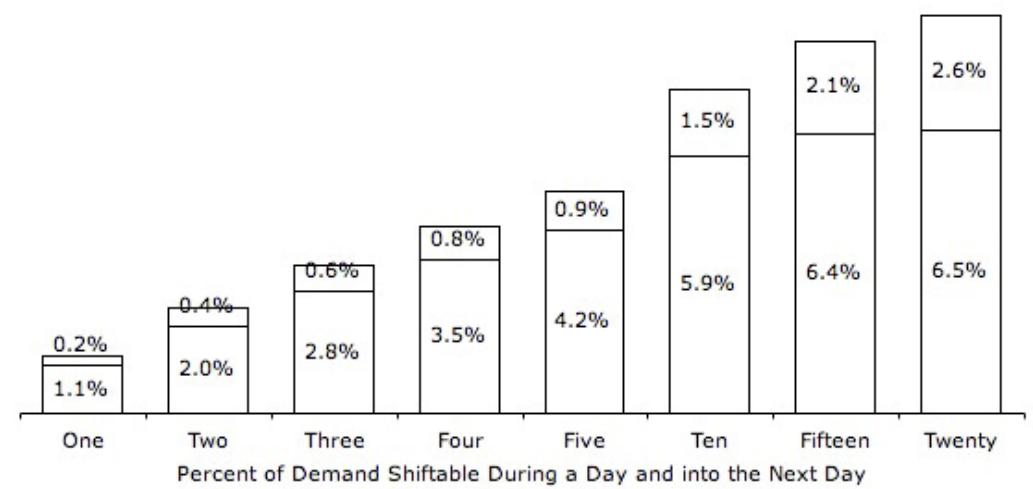

Figure 3: Additional displacement of diesel-generated electricity for a scenario of $3 \mathrm{x}$ wind and $1 \mathrm{x}$ hydro with intra-day and one-day delay responsive demand.

\subsection{Application of responsive demand analysis: investment decisions}

Returning to our opening discussion about the Azores Archipelago, recall that the current Governmental Goals state that the region is to obtain, in less than six years, $50 \%$ of the electricity supply from renewable and local resources for the aggregated consumption of the Archipelago. Hence, each island must make an investment decision on how to meet this goal. One application of the method illustrated here is to inform the decision makers about the tradeoffs between costs and benefits of different investment decisions.

Consider this hypothetical situation: the island of Flores would like to expand their wind farm or their hydro power plant but only has the funding to do one or the other. The decision is between tripling the capacity of the wind farm and doubling the capacity of the hydro power plant. From the analysis we performed 
here and displayed in Table 1, the baseline reduction of diesel-generated electricity is expected to be $39 \%$ for tripling the wind farm and $43 \%$ for doubling the hydro power plant.

However, if the investment cost for tripling the wind farm were less than that of doubling the hydro power plant, the decision makers could consider an additional option of whether to invest in a responsive demand program along with the wind farm expansion. Depending on the expected participation in the responsive demand program, a comparison between the benefits of investing in wind farm expansion and responsive demand program could be compared with the benefits of the investment in the hydro power plant. Fig. 4 illustrates this hypothetical situation and would quickly inform decision makers of the potential benefits of each investment decision.

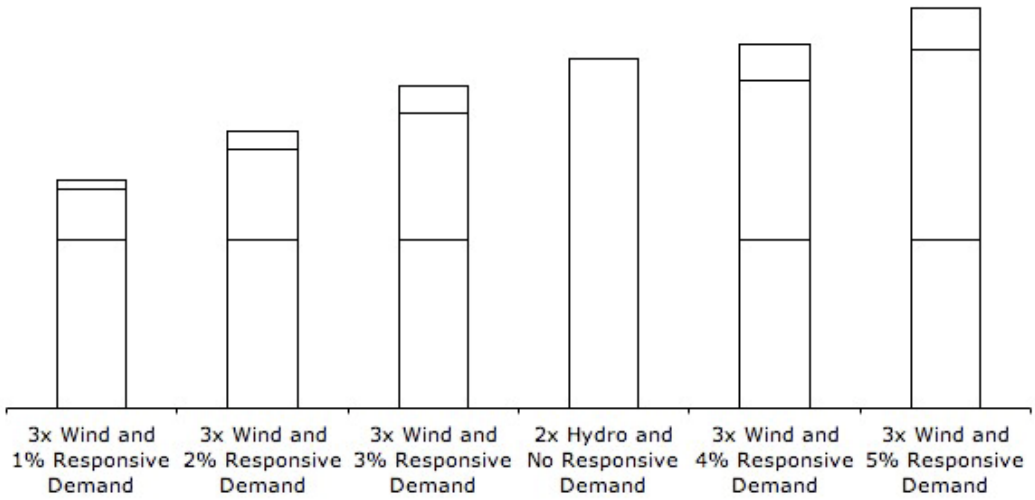

Figure 4: Comparison of displacement from tripling wind capacity and using various levels of responsive demand versus doubling hydro power plant capacity.

From the results displayed in fig. 4 , if $4 \%$ or more of the total demand on the island would be expected to participate in a responsive demand program, then the estimated total displacement of diesel-generated electricity from the tripling of the wind farm and developing a responsive demand program would exceed the estimated total displacement of diesel-generated electricity from the doubling of the hydro power plant. This side-by-side comparison of the expected benefits from various renewable expansion and responsive demand scenarios would provide a useful tool to quickly inform decision-makers of the tradeoffs between the expected costs and benefits of different investment options for meeting the goal of decreasing the island's fossil fuel usage.

\section{Conclusions and future work}

In this paper, we have shown that responsive demand can help increase the displacement of fossil fuel usage on an island by better utilizing the electricity generated by local and renewable generation sources, especially when large-scale 
and long-term storage systems are infeasible or impractical. In the example scenario illustrated in the paper, an additional 5 to $10 \%$ of the annual dieselgenerated electricity was shown to be displaceable via responsive demand adjusting the aggregate demand curve to hours of excess renewable generation.

The method proposed here calculates an initial estimate of these fossil fuel displacement benefits under various scenarios of hypothetical renewable generation, which could in turn influence investment decisions regarding which local renewable sources of electricity should be expanded or developed. While the results presented in this paper are unique to the island of Flores, the method is easily transferable to other island settings with different options for local renewable sources of electricity generation. Although this particular model focused on wind power and hydro power, any combination of renewable generation sources could be included to reflect the unique generation potential for an island.

For the model illustrated in this paper, we assumed perfect information of electricity demand and generation levels from the wind farm and hydro power plant. In reality, this information will be at best a forecast of future demand and generation levels. Not including this stochastic nature means that the total fossil fuel displacement calculated here is simply an upper bound on the potential benefits of increasing renewable generation and of supporting the integration of those renewables with responsive demand.

Clearly, decisions made regarding the implementation of a responsive demand program will affect the actual amount of fossil fuel that is displaced. In particular, one key implementation question is: What real-time signals are required to elicit the necessary responsive demand? Will a time-varying pricing system be implemented? Will the grid operator directly control the end-users' demand? For an island, perhaps it would be sufficient to design a system that merely informs consumers of the future hours likely to have excess renewable generation.

Whatever information is ultimately sent to consumers, the stochastic nature of both electricity demand and renewable generation means that these forecasts will change regularly. A likely critical piece of any successful responsive demand program would be to encourage adoption of energy management systems that could automate end-users' consumption. In particular, research by the authors into how stochastic dynamic programming would likely increase the realized benefits of a responsive demand program is being pursued via development of their Energy Box model [11]. With this more detailed model of how end-users would adjust their consumption in response to real-time conditions on the grid, more accurate estimates of the potential benefits of responsive demand programs could be attained. However, in some situations, a simple method such as the one presented in this paper may provide a sufficient estimate of the benefits of a responsive demand program in a much shorter period of time.

\section{Acknowledgement}

The authors would like to thank the Fundação para Ciência e Tecnologia / MITPortugal Program for the financial support for the work reported in this paper 
and performed under the project "Power demand estimation and power system impacts resulting of fleet penetration of electric/plug-in vehicles" (FCT MITPt/SES- GI/ 008/ 2008).

\section{References}

[1] Zhang, K.M., Thomas, R.J., Bohm, M. \& Miller, M, An integrated Design approach for sustainable community development. Proceedings of the $42^{\text {nd }}$ Hawaii International Conference on System Sciences, 2009.

[2] Weisser, D. \& Garcia, R.S., Instantaneous wind energy penetration in isolated electricity grids: concepts and review. Renewable Energy 30, pp. 1299-1308, 2005

[3] Peças Lopes, J.A., Hatziargyriou, N., Mutale, J., Djapic, P. \& Jenkins, N. Integrating distributed generation into electric power systems: A review of drivers, challenges and opportunities. Electric Power Systems Research, 77, pp. 1189-1203, 2007

[4] Estanqueiro, A.I., Jesus J.M.F., Santos, Ricardo, J., Santos, A. \& Peças Lopes, J.A., Barriers (and solutions...) to very high wind penetration in power systems. IEEE, 2007.

[5] Kaldellis, J.K., Zafirakis, D. \& Kavadias, K., Techno-economic comparison of energy storage systems for islands autonomous electrical networks. Renewable and Sustainable Energy Reviews, 13, pp. 378-392, 2007.

[6] Bueno, C. \& Carta, J.A., Wind powered pump hydro storage systems, a mean of increasing the penetration of renewable energy in the Canary Islands. Renewable and Sustainable Energy Reviews, 10, pp 312-340, 2006.

[7] Hamidi, V., Li, F. \& Robinson, F., The effect of responsive demand in domestic sector on power system operation in the networks with high penetration of renewables. Power and Energy Society General Meeting Conversion and Delivery of Electrical Energy in the 21st Century - IEEE, pp. 1-8, 2008.

[8] Statistical Yearbook of the Azores Region - 2007, Azores Statistical Regional Service. http://estatistica.azores.gov.pt

[9] Program of the X Regional Government of Azores, pp 45-48. http://www.azores.gov.pt/

[10] Electricity consumption by region - data for 2008, Direcção Geral de Energia e Geologia. http://www.dgge.pt/

[11] Livengood, D. and Larson, R., The Energy Box: Locally Automated Optimal Control of Residential Electricity Usage. Service Science, 1(1), pp. 1-16, 2009. 